\title{
Immunohistochemical Detection of Macrophage Migration Inhibitory Factor in Fetal and Adult Bovine Epididymis: Release by the Apocrine Secretion Mode?
}

\author{
R. Eickhoff ${ }^{a}$ G. Jennemann ${ }^{a}$ G. Hoffbauer ${ }^{a} \quad$ M.-P. Schüring ${ }^{b}$ H. Kaltner ${ }^{b}$ \\ F. Sinowatz ${ }^{c}$ H.-J. Gabius ${ }^{b}$ J. Seitz ${ }^{a}$ \\ ${ }^{a}$ Department of Anatomy and Cell Biology, Philipps University Marburg, Marburg, ${ }^{\mathrm{b}}$ Institute of Physiological \\ Chemistry, and ${ }^{C}$ Institute of Veterinary Anatomy, Ludwig Maximilian University Munich, Munich, Germany
}

\section{Key Words}

Apocrine secretion - Epididymis · Spermatozoa

Macrophage migration inhibitory factor

\begin{abstract}
Originally defined as a lymphokine inhibiting the random migration of macrophages, the macrophage migration inhibitory factor (MIF) is an important mediator of the host response to infection. Beyond its function as a classical cytokine, MIF is currently portrayed as a multifunctional protein with growth-regulating properties present in organ systems beyond immune cells. In previous studies, we detected substantial amounts of MIF in the rat epididymis and epididymal spermatozoa, where it appears to play a role during post-testicular sperm maturation and the acquisition of fertilization ability. To explore its presence in other species not yet examined in this respect, we extended the range of studies to the bull. Using a polyclonal antibody raised against MIF purified from bovine eye lenses, we detected MIF in the epithelium of the adult bovine epididymis with the basal cells representing a prominently stained cell type. A distinct accumulation of MIF at the apical cell pole of the epithelial cells and in membranous vesicles localized in the lumen of the epididymal duct was obvious. In the fetal bovine epididymis, we also detected MIF in the ep-
\end{abstract}

ithelium, whereas MIF accumulation was evident at the apical cell surface and in apical protrusions. By immunoelectron microscopy of the adult bovine epididymis, we localized MIF in apical protrusions of the epithelial cells and in luminal membrane-bound vesicles that were found in close proximity to sperm cells. Although the precise origin of the MIF-containing vesicles remains to be delineated, our morphological observations support the hypothesis that they become detached from the apical surface of the epididymal epithelial cells. Additionally, an association of MIF with the outer dense fibers of luminal spermatozoa was demonstrated. Data obtained in this study suggest MIF release by an apocrine secretion mode in the bovine epididymis. Furthermore, MIF localized in the basal cells of the epithelium and in the connective tissue could be responsible for regulating the migration of macrophages in order to avoid contact of immune cells with spermatozoa that carry a wide range of potent antigens.

Copyright $(c) 2006$ S. Karger AG, Basel

\section{Abbreviations used in this paper}

MIF macrophage migration inhibitory factor

PBS phosphate-buffered saline

\begin{tabular}{ll}
\hline KARGER & ( ) 2006 S. Karger AG, Basel \\
Fax +4161306 1234 & \\
$\begin{array}{l}\text { E-Mail karger@karger.ch } \\
\text { www.karger.com }\end{array}$ & $\begin{array}{l}\text { Accessible online at: } \\
\text { www.karger.com/cto }\end{array}$
\end{tabular}




\section{Introduction}

Macrophage migration inhibitory factor (MIF, $12 \mathrm{kDa}$ ) was originally described as a T-cell-derived cytokine which inhibited the random migration of guinea pig peritoneal macrophages [Bloom and Bennett, 1966; David, 1966]. Over the years, the cytokine has been shown to be released by various immune cells playing a central role in the control of both innate and antigen-specific immunity [Weiser et al., 1989; Bernhagen et al., 1993; Calandra et al., 1994, 1998]. Exhibiting a proinflammatory activity, MIF has the unique ability to counter-regulate the immunosuppressive effects of glucocorticoids on immune responses [Calandra et al., 1995; Bacher et al., 1996]. Crystal structure analyses of the 115-amino acid protein have shown that MIF exists as a homotrimer forming a barrel structure with a positively charged core [Sun et al., 1996; Suzuki et al., 1996].

Its interaction with the $\alpha / \beta$-interferon antagonist sarcolectin and, of even wider general importance, with Jab1, a coactivator of activator protein 1 transcription, as well as its capability to bypass $\mathrm{p} 53$ functionality, resulting in a negative regulation of growth arrest and apoptosis, indicate that the range of MIF activities is not restricted to the immune system [Zeng et al., 1993, 1994a, b; Hudson et al., 1999; Kleemann et al., 2000]. MIF was detected in various endocrine organs like the anterior pituitary gland, adrenal gland, and pancreas [Bernhagen et al., 1993; Bacher et al., 1997; Waeber et al., 1997]. These data suggest important functions of MIF beyond the immune system, prompting us to analyze its expression in the reproductive tract. In previous studies, its presence had been detected in human granulosa cells and in bovine corpus luteum [Wada et al., 1997, 1999; Bove et al., 2000]. Regarding rat testis, MIF was found to be synthesized by the Leydig cells [Meinhardt et al., 1996, 1999]. The modulation of inhibin production of Sertoli cells by MIF suggests a role of the polypeptide as a paracrine mediator of testicular function [Meinhardt et al., 1996]. Furthermore, Leydig cell ablation by the Leydig cell-specific toxin ethane dimethane sulfonate leads to a compensatory MIF production by the Sertoli cells which were negative in untreated rat testes [Meinhardt et al., 1999]. After repopulation of the interstitium by immature Leydig cells, MIF production by the Leydig cells was upregulated resulting in an immunostaining pattern identical to that of untreated testes [Meinhardt et al., 1999].

Studying the epithelium of rat epididymis, the principal cells have been delineated as the source of the cytokine, whereas the basal cells as well as the stromal cells were MIF negative [Eickhoff et al., 2001]. In addition, a differential distribution pattern with highest amounts of MIF in the caput region decreasing in more distal parts of the epididymis was described in that report, and MIF was also localized in vesicles detectable in the epididymal fluid [Eickhoff et al., 2001]. In epididymal spermatozoa, MIF is associated with the outer dense fibers surrounding the axoneme of the midpiece and principal piece of the flagellum [Eickhoff et al., 2001]. Together with the localization of MIF, spatially restricted to the cytoplasm of epididymal epithelial cells [Eickhoff et al., 2001], and with the lack of any N-terminal signal sequence for translocation into the endoplasmic reticulum, these data strongly suggest a nonclassical secretion mode via vesicles (aposomes) pinching off from the apical plasma membrane of the epithelial cells and released into the epididymal fluid. As shown by immunofluorescence microscopy, MIF was only detectable in epididymal sperm but not in testicular sperm. Therefore, an uptake of epididymal MIF by maturating spermatozoa is suggested [Eickhoff et al., 2001]. The hypothesis of a vesicular transfer of MIF from the epididymal epithelial cells to the spermatozoa by fusion of vesicles pinched off from the epithelial plasma membrane with the sperm membrane is based on the cell-to-cell-transfer model of Kirchhoff and Hale [1996] and on the apocrine mode of secretion described for epididymal MIF acquired by spermatozoa during epididymal transit [Frenette et al., 2002, 2003]. Very recently, the role of these membrane-bound vesicles in sperm maturation was reviewed by Sullivan et al. [2005]. Transferred to the epididymal sperm cells, MIF is supposed to affect the sperm maturation process during the transit along the epididymal duct. Recently, we were able to show that MIF in fact plays an important role in the post-testicular maturation of rat spermatozoa by supporting the elimination of zinc from zinc-mercaptide complexes and by influencing the redox state of protein-bound sulfhydryl groups in sperm cells isolated from rat epididymis, thus contributing to the acquisition of fertilization ability [Eickhoff et al., 2004]. For humans, an involvement of MIF in the acquisition of sperm mobility was shown [Eickhoff et al., 2004; Frenette et al., 2005].

Prompted by the availability of a polyclonal antibody raised against MIF purified from bovine lenses, the aim of the present study was to investigate MIF localization in bovine epididymis, with a focus on the hypothesis for an apocrine secretion mode and on the relevance of MIF for the sperm maturation process. 


\section{Materials and Methods}

Animals and Reagents

Male adult Wistar rats were purchased from Charles River, Kisslegg, Germany. Fetal bull epididymis as well as adult bull testis and epididymis were obtained at the local slaughterhouse. Recombinant mouse MIF was a gift from Dr. M. Bacher (Marburg, Germany).

\section{Tissue Preparation}

Ten male adult Wistar rats (ranging in body weight from 290 to $310 \mathrm{~g}$ ) were anesthetized and killed by $\mathrm{CO}_{2}$ asphyxiation. Thereafter, testes and epididymides were removed. Adult bull testis and epididymis obtained at the local slaughterhouse were kept on ice for transportation to the laboratory. All successive steps were carried out at $4^{\circ} \mathrm{C}$. Epididymal fluid was obtained by a retrograde perfusion with Tris-sucrose buffer (10 $\mathrm{m} M$ Tris- $\mathrm{HCl}, 250 \mathrm{~m} M$ sucrose, $1 \mathrm{~m} M$ EDTA, and $1 \mathrm{~m} M$ Pefabloc SC protease inhibitor; $\mathrm{pH}$ 7.4) using a syringe inserted into the scrotal portion of the vas deferens. This procedure was performed with great care to avoid blood cell contamination resulting from injured blood vessels. Epididymal spermatozoa were separated from epididymal fluid by centrifugation at $800 \mathrm{~g}$ for $10 \mathrm{~min}$ and washed twice using Trissucrose buffer. Following sedimentation of the sperm cells, the epididymal fluid was centrifuged at 2,000 $g$ for 20 min to eliminate fragments. The resulting supernatant was used for Western blot analysis.

To obtain total tissue extracts, decapsulated testis, caput, corpus and cauda epididymidis were minced with scissors. Spermatozoa were separated from epididymal tissue by filtration through a nylon net. Following homogenization of the tissue by a Potter-Elvehjem homogenizer (Braun Biotech, Melsungen, Germany), tissue aggregates and cell debris were removed by centrifugation at $200 \mathrm{~g}$ for $10 \mathrm{~min}$. The supernatants were collected and the cytosolic fraction was obtained by ultracentrifugation at $100,000 \mathrm{~g}$ for $30 \mathrm{~min}$. Protein content of the samples was analyzed according to the colorimetric method described by Bradford [1976].

\section{Production of the Antibody}

Bovine MIF was purified from supernatants of lenses by a series of chromatographic steps starting with phenyl Sepharose as described previously [Rosengren et al., 1996]. Following chromatographic procedures, remaining contaminants were removed by high-resolution preparative SDS gel electrophoresis yielding the protein band for immunization. A polyclonal antibody preparation was then raised in rabbits immunized with $150 \mu \mathrm{g}$ protein in complete Freund's adjuvant and further booster injections using Freund's incomplete adjuvant 4 and 7 weeks after the first immunization. The immunoglobulin $\mathrm{G}$ fraction from serum was purified by chromatography on protein A Sepharose 4B (Pharmacia, Freiburg, Germany) [Choufani et al., 2001; Kaltner et al., 2002; Legendre et al., 2003]. Running ELISA and Western blotting determined the titer and ascertained the specificity toward the antigen [Andre et al., 1999; Kaltner et al., 2002].

\section{$S D S-P A G E$}

Samples of testicular and epididymal cytosol, epididymal duct fluid, and epididymal spermatozoa were diluted 1:2 in reducing sample buffer containing 2\% (w/v) SDS and $0.2 \%(\mathrm{w} / \mathrm{v})$ dithio- threitol. Proteins were separated on a NuPAGE 4-12\% Bis-Tris gel (Invitrogen, Carlsbad, Calif., USA).

\section{Western Blot Analysis}

After gel electrophoretic separation, the proteins were transferred onto a $0.2-\mu \mathrm{m}$ nitrocellulose membrane (Schleicher and Schuell, Dassel, Germany). In order to quantify the protein amount transferred to the nitrocellulose, the membrane was stained by Ponceau S. Following a blocking step to saturate the protein-binding capacity, the membrane was incubated with the primary antibody raised against bovine $\operatorname{MIF}(1: 1,500)$ overnight at room temperature. After washing, the membrane was incubated with peroxidaseconjugated goat anti-rabbit immunoglobulin $\mathrm{G}$ antibody (Cappel, Durham, N.C., USA, 1:10,000) for $1 \mathrm{~h}$ at room temperature. Immunoreactive bands were visualized using a commercial enhanced chemoluminescence system (Amersham, Braunschweig, Germany).

\section{Immunohistochemistry}

Testes and epididymides of fetal and adult bull were removed. The age of the fetus was estimated on the basis of crown-rump length, which was $87 \mathrm{~cm}$, equaling a developmental stage directly before birth [Rüsse and Sinowatz, 1991]. Immediately after removal, tissues were fixed with Bouin's solution, dehydrated, and embedded in paraffin. Sections were cut at 5 to $6 \mu \mathrm{m}$ thickness, deparaffinized, and subsequently passed in a stepwise manner through solutions with decreasing concentrations of alcohol in water. Pretreatment with $3 \% \mathrm{H}_{2} \mathrm{O}_{2}$ in phosphate-buffered saline (PBS) was performed for $30 \mathrm{~min}$ to inactivate endogenous peroxidases. Tissue sections were preincubated in blocking solution (Rotiblock, Roth, Karlsruhe, Germany) in order to minimize antigen-independent antibody binding, followed by an incubation at $4^{\circ} \mathrm{C}$ overnight with the polyclonal MIF antibody diluted 1:6,000 in the blocking solution. The antibody bound was visualized using the Universal LSAB 2 horseradish peroxidase kit according to the manufacturer's instructions (Dako, Hamburg, Germany). Sections were stained with the chromogenic substrate 3,3'-diaminobenzidine. Antiserum preabsorbed with recombinant MIF in excess or incubation with PBS instead of the primary antibody were used as negative controls. Specimens were lightly counterstained with Meyer's hematoxylin and mounted in aqueous mounting media for light microscopic observations.

\section{Immunoelectron Microscopy}

Immediately after removal, small bovine epididymal tissue fragments were fixed in a mixture of $1.25 \%$ paraformaldehyde, $2.5 \%$ glutaraldehyde, and $0.05 \%$ picric acid in $100 \mathrm{mM}$ cacodylate buffer ( $\mathrm{pH} 7.3$ ) overnight. Immunoelectron microscopy on ultrathin sections was performed as described previously [Steinhoff et al., 1994]. Briefly, fixed specimens were dehydrated in a graded series of ethanol and propylene oxide, and embedded in epoxy resin. Ultrathin sections $(50 \mu \mathrm{m})$ were cut on a Reichert Ultracut ultramicrotome. Sections were incubated with anti-MIF antibody (1:50) and subsequently with colloidal gold-coated anti-rabbit immunoglobulin G (1:50; Biocell, Cardiff, UK). Specimens were briefly stained with uranyl acetate and lead citrate and examined in a Zeiss EM 10 electron microscope. Preimmune serum or PBS instead of the primary antibody were used as negative controls.
Eickhoff/Jennemann/Hoffbauer/ Schüring/Kaltner/Sinowatz/Gabius/Seitz 


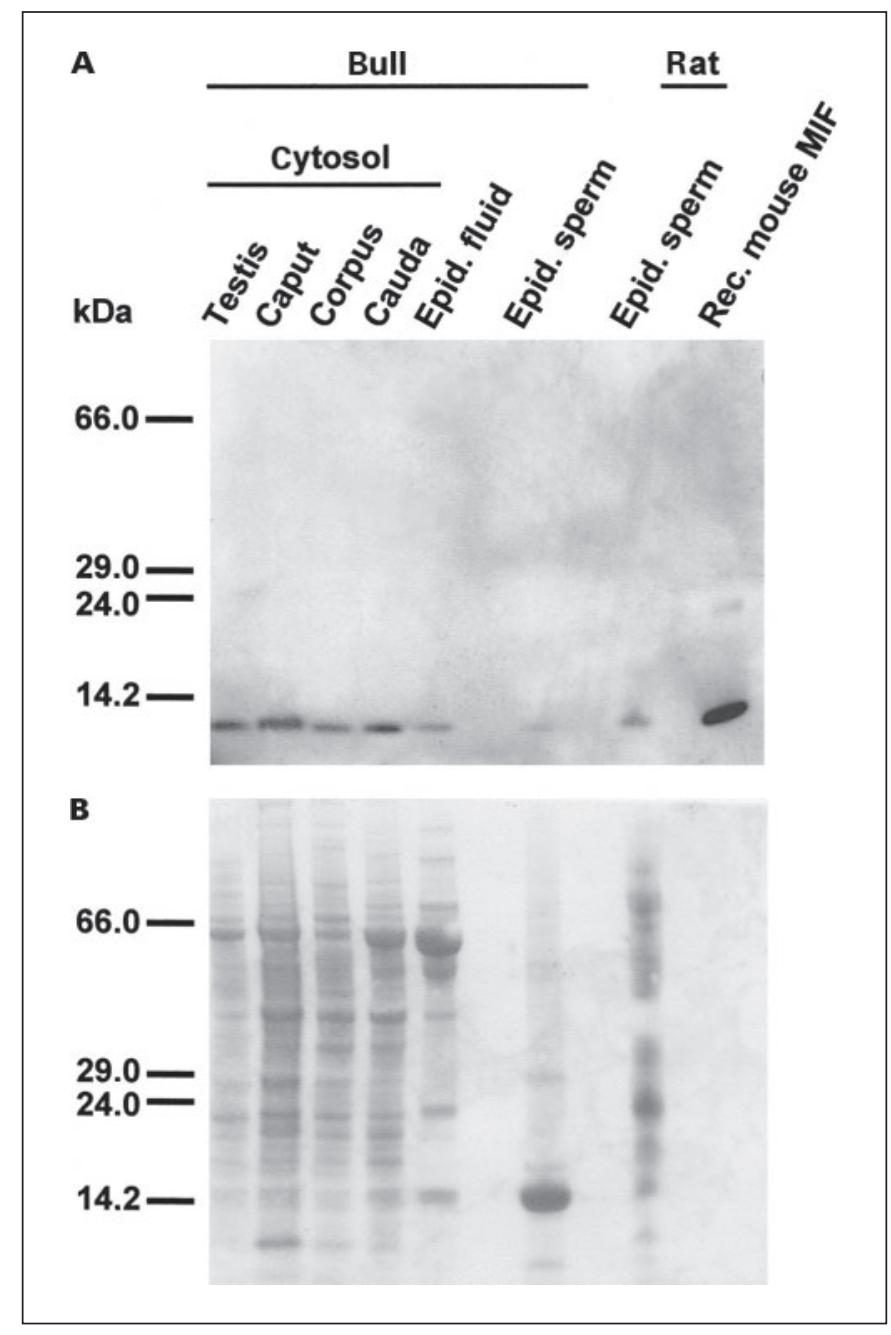

Fig. 1. A Western blot analysis of extracts of testis and different sections of epididymis (Epid.). The blot was incubated with an antibody directed against bovine MIF. The immunoreactive band at $12 \mathrm{kDa}$ comigrated with recombinant (Rec.) mouse MIF, documenting cross-reactivity of the antibody for MIF originating from bull, mouse and rat. B Corresponding Ponceau S staining for visualization of the protein quantities transferred to the nitrocellulose membrane.

\section{Results}

Detection of MIF in Epididymal Cytosol, Epididymal Fluid, and Epididymal Spermatozoa

The presence of MIF in various parts of the adult bovine reproductive tract was shown by Western blot analysis using an antibody raised against purified MIF from bovine eye lenses. All fractions of testicular and epididymal cytosol, epididymal duct fluid, and spermatozoa isolated from the bovine epididymis revealed an immuno- reactive band at $12 \mathrm{kDa}$, which migrates with mobility identical to recombinant mouse MIF (fig. 1A). Considering the protein quantities transferred to the nitrocellulose membrane (fig. 1B), a differential distribution pattern of MIF along the epididymal segments could not be observed.

In order to address the issue of potential cross-reactivity between rat, mouse and bovine MIF harboring 90\% sequence homology, we also tested the immunoreactivity of rat MIF with the bull protein-specific antibody. By Western blot analysis, spermatozoa isolated from rat epididymis showed a single band at $12 \mathrm{kDa}$ (fig. 1A). These data clearly verified an antigenic cross-reactivity between the three species detected by this polyclonal antibody.

\section{Immunohistochemical Localization of MIF}

Using the anti-MIF antibody for immunohistochemical localization of the protein in different segments of the adult bovine epididymis, the epithelium of the caput epididymidis showed weak immunoreactivity. Compared with the faint staining of the epithelium, an accumulation of MIF at the apical cell pole of several epithelial cells was observed (fig. 2A). A further remarkable result concerned the epididymal duct lumen of the caput region. Here, many MIF-containing vesicles pinching off from the apical plasma membrane were detected (fig. 2B). In the corpus epididymidis, a homogeneous staining of the epithelium was apparent with a distinct accumulation of MIF at the apical pole of the epithelial cells (fig. 2C). Enhanced magnification revealed apical blebs pinching off from the epithelial cells and intraluminal vesicles in direct association with the epididymal sperm cells (fig. 2D). In the cauda region, compared with the lesser staining intensity of the cytoplasm, MIF again accumulated at the apical domain of the epithelial cells. In the duct lumen, substantial amounts of MIF-containing vesicles were found in close contact with the spermatozoa (fig. 2E). In contrast to data on rat epididymis [Eickhoff et al., 2001], the basal cells in bovine epididymis were strongly immunopositive for MIF, and it was also detected in stromal cells as documented in figure 2A, E.

By immunohistochemical investigation of fetal epididymis, we found MIF presence in the epithelium of all investigated segments: caput (fig. 3A), corpus (fig. 3B), and cauda (fig. 3C). As seen in the adult epididymis, a distinct accumulation of MIF at the apical cell surface and in apical protrusions was invariably observed, suggesting a release of MIF by apocrine secretion not only in the adult bull but also in the prenatal state of development. 

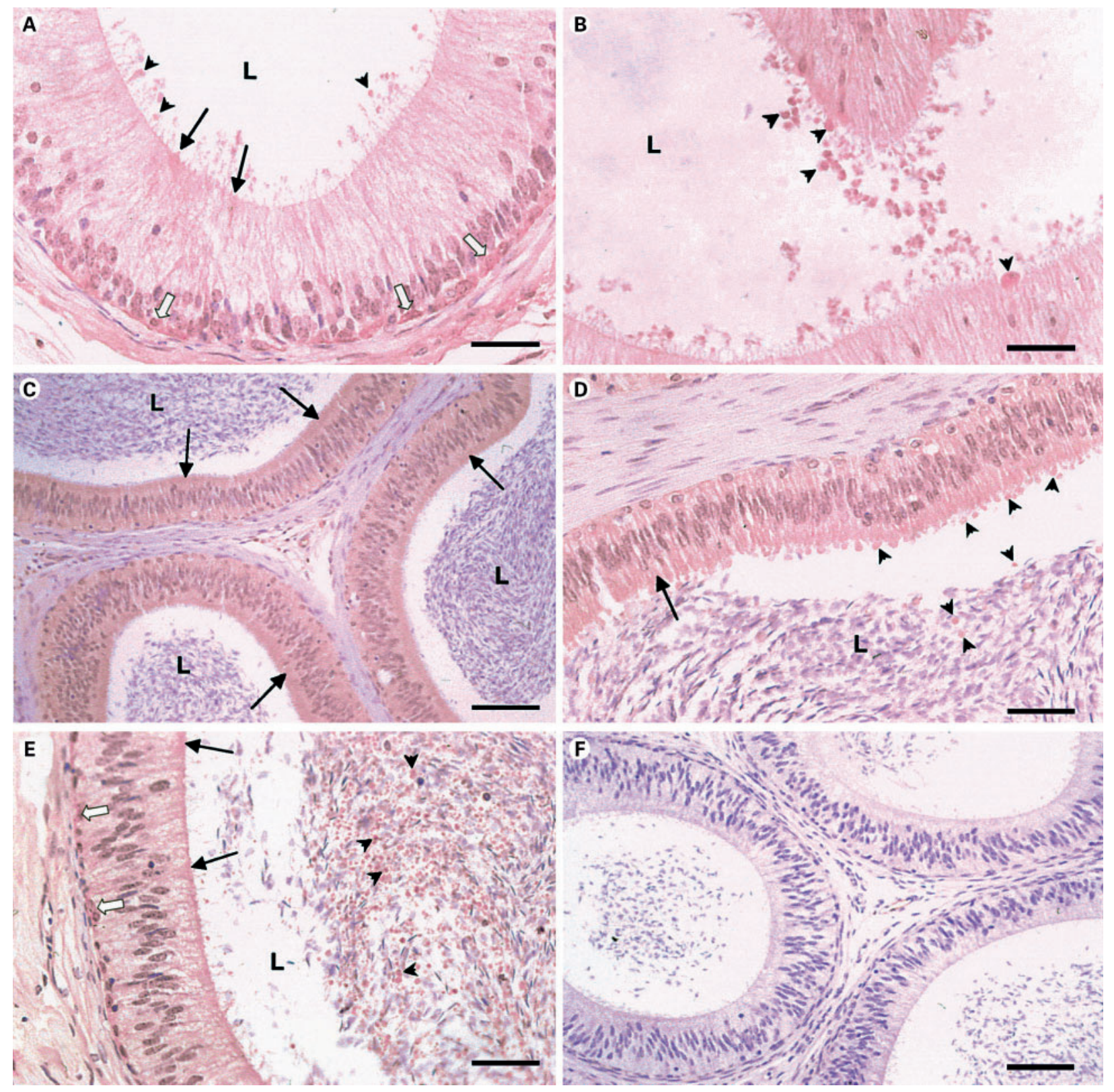

Fig. 2. Immunohistochemical localization of MIF in the adult bovine epididymis. A, B Caput epididymidis. There is a weak staining in the epithelium with an accumulation of MIF at the apical pole of several epithelial cells (arrows). The basal cells of the epithelium are strongly immunopositive for MIF (white arrows), whereas the stromal part is immunoreactive as well. MIF is also detectable in luminal vesicles pinching off from the apical surface membrane (arrowheads). C, D Corpus epididymidis. Exhibiting a homogeneous staining of the whole epithelium, MIF is clearly concentrated towards the lumen of the epididymal duct showing strong immunoreactivity at the border of the lumen (arrows). At enhanced magnification (D), MIFcontaining apical protrusions and MIF-positive intraluminal vesicles interacting with the luminal sperm cells are visible (arrowheads). E Cauda epididymidis. Again, MIF which is localized in the epithelium clearly accumulates at the apical cell surface (arrows). In the lumen, vesicles containing MIF appear abundantly and are directly associated with the spermatozoa (arrowheads). The basal cells of the epithelium reveal a strong immunoreactivity for MIF (white arrows). MIF was also detectable in the stromal part. F Negative control using PBS instead of primary antibody. L = Epididymal lumen. Scale bars: $20 \mu \mathrm{m}$ (A, D, E), $10 \mu \mathrm{m}$ (B), $40 \mu \mathrm{m}$ (C, F). 

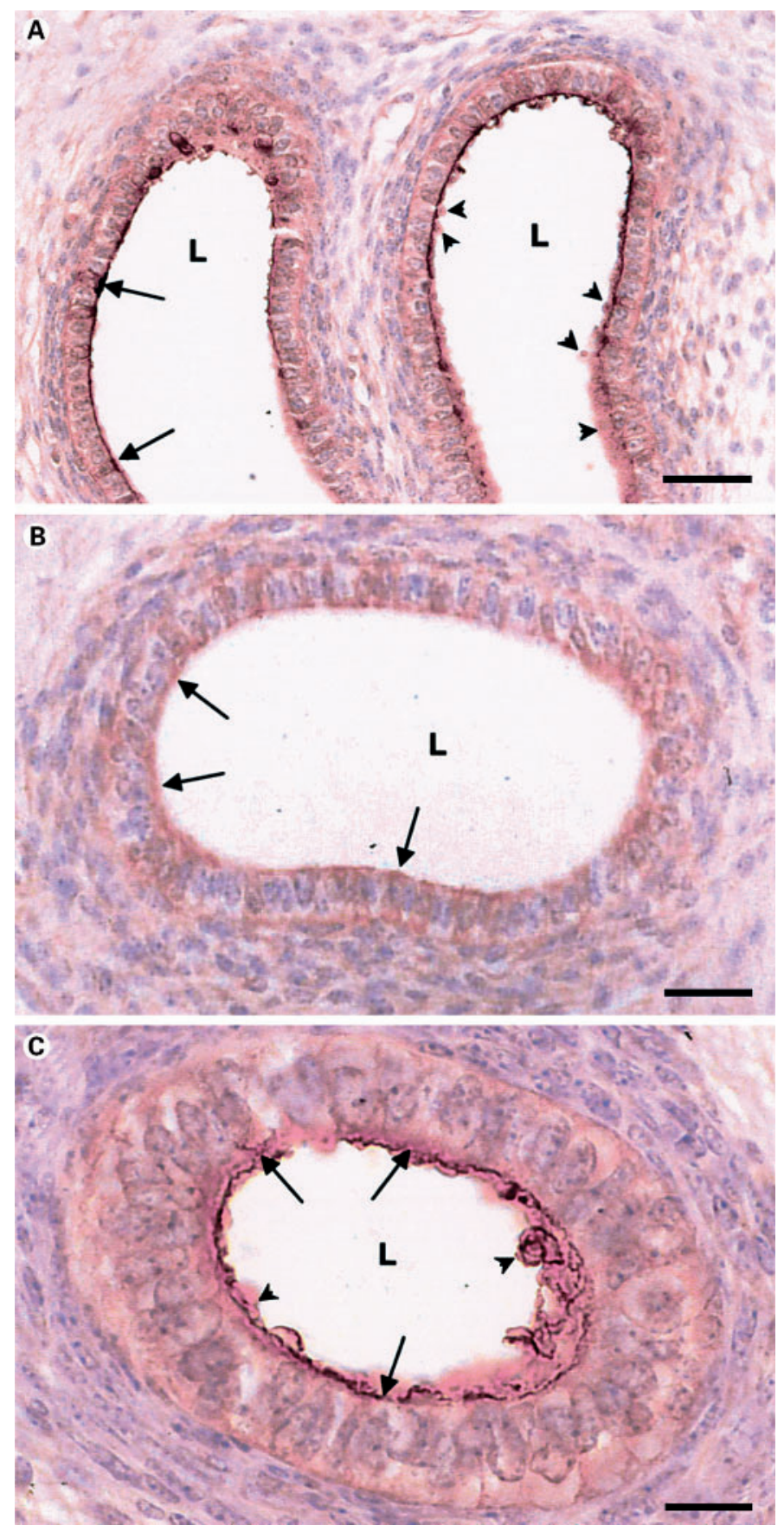

Fig. 3. Immunohistochemical localization of MIF in the fetal bovine epididymis. Caput epididymidis (A), corpus epididymidis (B), cauda epididymidis (C). In the prenatal state of bovine development, MIF is detectable in the epididymal epithelium with a clear accumulation at the apical pole of the epithelial cells (arrows). MIF-containing apical protrusions are pinching off from the apical plasma membrane (arrowheads). L = Epididymal lumen. Scale bars: $80 \mu \mathrm{m}$ (A), $40 \mu \mathrm{m}$ (B), $20 \mu \mathrm{m}$ (C).

MIF in the Male Bovine Reproductive Tract
Immunoelectron Microscopical Localization of MIF

To further analyze the localization of MIF at the ultrastructural level, ultrathin sections of bovine epididymis were incubated with our specific anti-MIF antibody. For an overview, sections were routinely incubated with a secondary antibody conjugated to $20-\mathrm{nm}$ gold particles (fig. 4). Specific MIF labeling was demonstrated in the cytoplasm of the principal cells, in cellular protrusions which were formed at the apical surface of the epithelial cells (fig. 4A, C), as well as in luminal membrane-bound vesicles of different sizes (2-5 $\mu \mathrm{m}$ diameter) (fig. 4B). MIF-positive vesicles were shown to be in direct contact to spermatozoa passing along the epididymal duct (fig. 4B). According to our experience, staining intensity can sometimes be improved by the use of smaller gold particles. Therefore, we have performed an additional immunoreaction with application of a specific secondary antibody conjugated to 10 -nm gold particles. Our results demonstrated a stronger labeling of the luminal vesicles (fig. 5A). In addition, MIF was shown to be associated with the outer dense fibers surrounding the axoneme of the midpiece and principal piece of the flagellum of luminal spermatozoa (fig. 5B).

\section{Discussion}

A substantial amount of data has accumulated over the years demonstrating the pleiotropic roles of MIF beside its typical functions in the immune system. However, only little is known about its mode of secretion and its function in the male reproductive tract. The aim of our study was to analyze the localization of MIF in the bovine epididymis, especially with respect to a possible secretion mode. For immunohistochemical staining, we have used a novel antibody raised against MIF purified from bovine lenses. In order to verify its specificity, we first performed Western blot analysis demonstrating MIF presence in the bovine testis and epididymis as well as in spermatozoa isolated from the epididymal duct. In contrast to the heterogeneous expression pattern in rat [Eickhoff et al., 2001], the relative abundance of MIF was similar in all regions of the bovine epididymis. Antigenic cross-reactivity of the antibody between MIF of rat, mouse and bovine origin was obvious. Using the antiserum for immunohistochemical analyses of the bovine epididymis, we detected MIF in the epithelium of the adult and the fetal epididymis. Within the epithelium of the adult caput epididymidis, we observed few cells with a more intense immunoreactivity at their apical cell poles. 

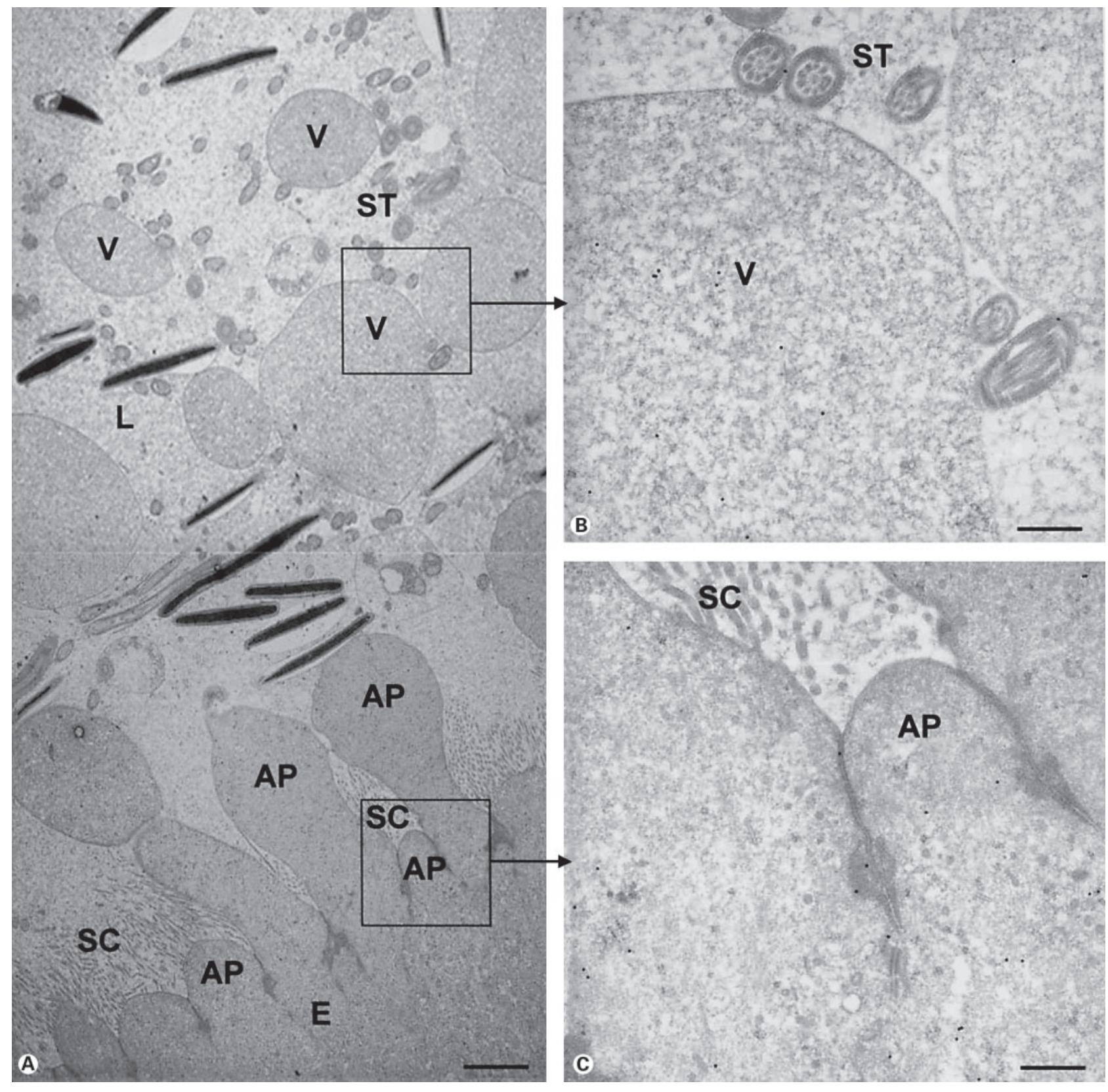

Fig. 4. Immunoelectron microscopical detection of MIF in the adult bovine epididymis using 20-nm gold particles. A The apical surface of the epithelial cells shows protrusions reaching the luminal compartment, where membrane-bound vesicles are localized in close proximity to the epididymal spermatozoa. B, C High-power magnification of selected regions of the cell surface and the luminal compartment shows specific MIF staining in the apical protrusions and the luminal vesicles localized in direct contact with epididymal spermatozoa. $\mathrm{AP}=$ Apical protrusions; $\mathrm{E}=$ epithelium; $\mathrm{L}=$ epididymal lumen; $\mathrm{SC}=$ stereocilia; $\mathrm{ST}=$ sperm tails; V = membrane-bound vesicles. Scale bars: $2.7 \mu \mathrm{m}(\mathbf{A}), 540 \mathrm{~nm}(\mathbf{B}, \mathbf{C})$.

The epithelium of the epididymal duct primarily consists of principal and basal cells, as well as a few apical cells that are characterized by the apical location of the nucleus, many mitochondria in the apical cytoplasm, and few microvilli at the luminal border [Goyal, 1985]. To date, we have no specific marker for discrimination of these three epithelial cell types. Therefore, the increased intensity of MIF immunoreactivity in a subset of epithelial 

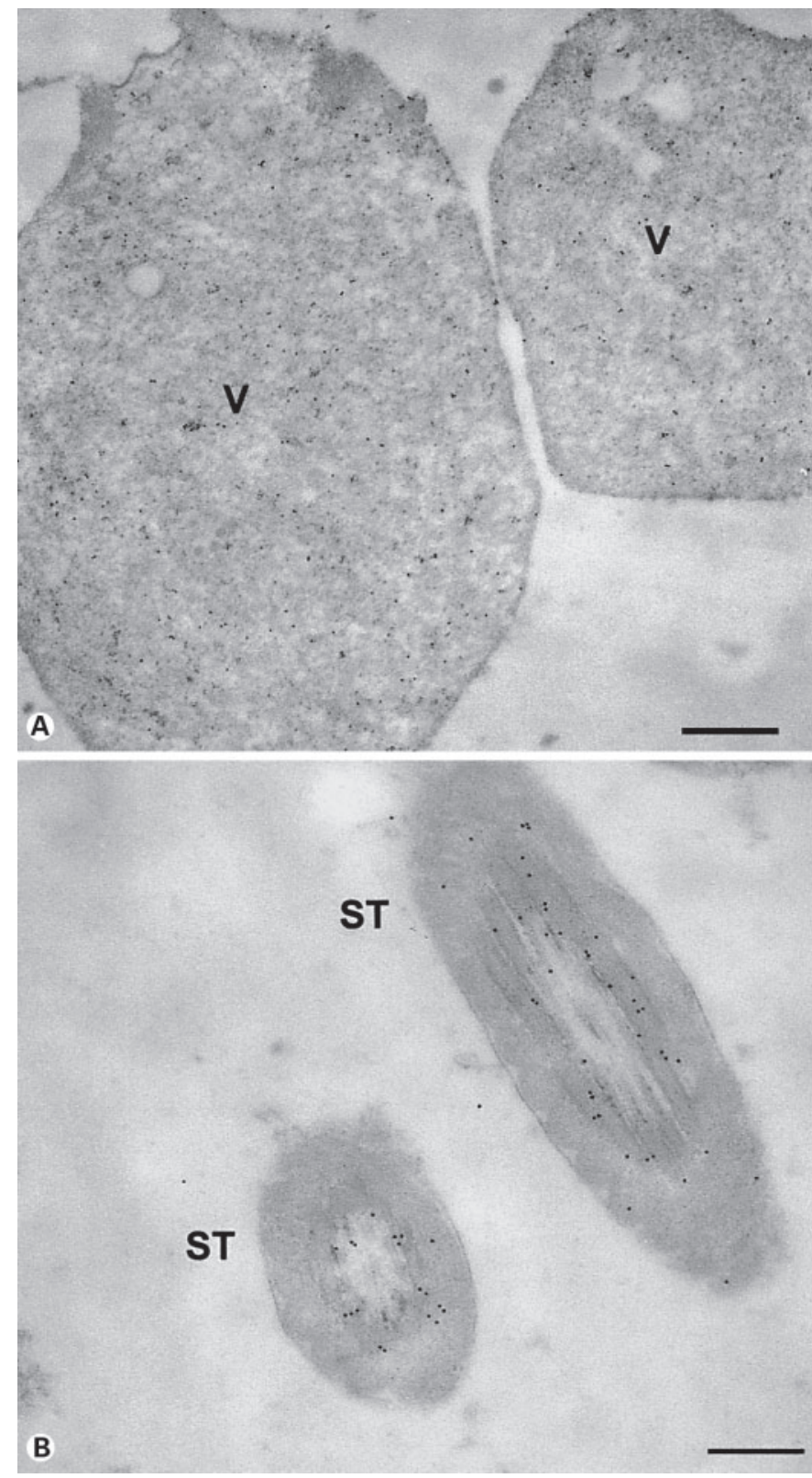

Fig. 5. Immunoelectron microscopical detection of MIF in epididymal spermatozoa using 10-nm gold particles. MIF immunoreactivity is localized in luminal vesicles $(\mathbf{A})$ and in the outer dense fibers surrounding the axoneme of the midpiece and principal piece of the flagellum (B). ST = Sperm tails; V = membrane-bound vesicles. Scale bars: $450 \mathrm{~nm}$ (A), $100 \mathrm{~nm}$ (B).

cells does not allow to differentiate between principal and apical cells. In line with earlier observations in the adult rat [Eickhoff et al., 2001], we detected an abundance of MIF-containing vesicles in the lumen of the bovine epi- didymis. These membrane-bound vesicles were not only localized in the immediate vicinity of the epididymal sperm cells, they were also present in sections of the epididymis containing fewer spermatozoa. This result indicates that these vesicles are no cytoplasmic droplets which were released from the epididymal sperm cells. We rather suggest that MIF-containing vesicles originate from the apical cell membrane of the epididymal epithelial cells by formation of protrusions. Apical protrusions subsequently get pinched off by an unknown mechanism to be released into the epididymal fluid. In order to study the concept of MIF release by vesicles pinched off from the epididymal epithelial cells, we performed immunoelectron microscopy. The data obtained on the adult bovine epididymis clearly demonstrated MIF-positive apical protrusions of the epithelial cells and MIF-containing membrane-bound vesicles of different sizes $(2-5 \mu \mathrm{m}$ diameter). Since epididymal MIF was localized in the cytoplasmic compartment of the epithelial cells and lacks a $\mathrm{N}$-terminal signal sequence for the translocation into the endoplasmic reticulum, release by a nonclassical mode of secretion is likely [Eickhoff et al., 2001]. In 1988, Agrawal and Vanha-Perttula described a release of membrane-bound vesicles into the secretory fluid of the lumen of the bovine epididymis [Agrawal and Vanha-Perttula, 1988]. The concept for a non-classical route of protein secretion, also known as 'apocrine secretion', has already been proposed for different parts of the male reproductive tract, e.g., the coagulating gland and the dorsal prostate of the rat [Seitz et al., 1990; Aumüller et al., 1991; Steinhoff et al., 1994; Wilhelm et al., 1998], as well as the seminal vesicle and the ductus deferens [Kaunisto et al., 1990; Manin et al., 1995]. The MIF-containing luminal vesicles were localized in close contact to the luminal sperm cells (fig. 4C). Additionally, we found MIF immunoreactivity in the outer dense fibers of the middle and principal piece of luminal spermatozoa, confirming the faint immunoreactivity of spermatozoa demonstrated by Western blot analysis (fig. 1). Taken together, we have shown the presence of MIF immunoreactivity in apical protrusions of the epididymal epithelium, in vesicles within the epididymal fluid, and in epididymal spermatozoa. Data of former studies indicate a cell-to-cell transfer of MIF from epididymal epithelial cells to spermatozoa by such membranous vesicles [Eickhoff et al., 2001]. Since protein constituents of the membranous vesicles can be transferred to luminal sperm cells [Frenette et al., 2002; Sullivan et al., 2005], an uptake of MIF into the sperm cells after fusion of the vesicular membrane with the sperm membrane is likely. A similar type of transfer 
from the epididymal epithelium to sperm cells was shown for the human epididymal product, HE 5, a small glycosylphosphatidylinositol-anchored glycopeptide secreted by epididymal principal cells [Kirchhoff et al., 1994, 1996].

Our immunohistochemical studies of the fetal epididymis showed an accumulation of MIF in apical protrusions. During the course of prenatal differentiation, the first generation of Leydig cells produces a comparatively high level of androgens in the fetus. The production of MIF in the prenatal epididymis might be attributed to this early wave of androgen secretion. However, the function of MIF during fetal development of the male reproductive tract remains to be delineated.

Comparison of MIF immunoreactivity in the bovine and rat epididymis revealed a difference in localization patterns. In contrast to rat [Eickhoff et al., 2001], the basal cells of the bovine caput and cauda region showed an intense labeling by the MIF-specific antibody. In addition, the connective tissue was immunopositive for MIF. The basal cells represent an epithelial cell type of largely unknown function, which adheres the basement membrane. MIF localized in the basal cells and in the stromal compartment could be responsible for regulating the migration of macrophages that under nonpathological conditions are rarely found in the epididymal duct lumen [Cooper, 1999]. Spermatozoa carry a wide range of potent antigens that can easily trigger an autoimmune response [Cropp and Schlaff, 1990; Meinertz et al., 1991; Bronson and Fusi, 1994]. Therefore, the contact of immune cells with spermatozoa must be avoided not only in the testis but all along the excretory genital duct system as well. So far, little attention has been paid to the presence of a blood-epididymis barrier formed by epithelial tight junctions [Howards et al., 1976; Hoffer and Hinton, 1984; Agarwal and Hoffer, 1989]. The discrepancy in the localization pattern of MIF between rat and bull may be due to the exceptional immune status of the rat [Calne, 2000].

Taken together, the bovine epididymis represents an interesting organ for the analysis of the pleiotropic function of MIF. Furthermore, the bovine epididymis could be a model system for the investigation of the apocrine secretion mode.

\section{Acknowledgements}

We are grateful to Prof. Andreas Meinhardt for his support in various parts of this work.

\section{References}

Agrawal, Y., T. Vanha-Perttula (1988) Electron microscopic study of the secretion process in bovine reproductive organs. J Androl 9: 307 316.

Agarwal, A., A.P. Hoffer (1989) Ultrastructural studies on the development of the blood-epididymis barrier in immature rats. $\mathrm{J}$ Androl 10 . 425-431.

Andre, S., S. Kojima, N. Yamazaki, C. Fink, H. Kaltner, K. Kayser, H.-J. Gabius (1999) Galectins- 1 and -3 and their ligands in tumor biology. Non-uniform properties in cell-surface presentation and modulation of adhesion to matrix glycoproteins for various tumor cell lines, in biodistribution of free and liposomebound galectins and in their expression by breast and colorectal carcinomas with/without metastatic propensity. J Cancer Res Clin Oncol 125: 461-474.

Aumüller, G., M. Bergmann, J. Seitz (1991) Immunohistochemical distribution of sulfhydryl oxidase in the human testis. Cell Tissue Res 266: $23-28$
Bacher, M., C.N. Metz, T. Calandra, K. Mayer, J. Chesney, M. Lohoff, D. Gemsa, T. Donnelly, R. Bucala (1996) An essential regulatory role for macrophage migration inhibitory factor in T-cell activation. Proc Natl Acad Sci USA 93: 7849-7854.

Bacher, M., A. Meinhardt, H.Y. Lan, W. Mu, C.N Metz, J.A. Chesney, T. Calandra, D. Gemsa, T. Donnelly, R.C. Atkins, R. Bucala (1997) Migration inhibitory factor expression in experimentally induced endotoxemia. Am J Pathol 150: 235-246

Bernhagen, J., T. Calandra, R.A. Mitchell, S.B. Martin, K.J. Tracey, W. Voelter, K.R. Manogue, A. Cerami, R. Bucala (1993) MIF is a pituitary-derived cytokine that potentiates lethal endotoxaemia. Nature 365: 756-759.

Bloom, B.R., B. Bennett (1966) Mechanism of a reaction in vitro associated with delayed-type hypersensitivity. Science 153: 80-82.

Bove, S.E., M.G. Petroff, M. Nishibori, J.L. Pate (2000) Macrophage migration inhibitory factor in the bovine corpus luteum: characterization of steady-state messenger ribonucleic acid and immunohistochemical localization. Biol Reprod 62: 879-885.
Bradford, M.M. (1976) A rapid and sensitive method for the quantitation of microgram quantities of protein utilizing the principle of proteindye binding. Anal Biochem 72: 248-254.

Bronson, R.A., F.M. Fusi (1994) Autoimmunity to sperm antigens. Allergy Clin North Am 14: 773-786.

Calandra, T., J. Bernhagen, R.A. Mitchell, R. Bucala (1994) The macrophage is an important and previously unrecognized source of macrophage migration inhibitory factor. J Exp Med 179: 1895-1902.

Calandra, T., J. Bernhagen, C.N. Metz, L.A. Spiegel, M. Bacher, T. Donnelly, A. Cerami, R. Bucala (1995) MIF as a glucocorticoid-induced modulator of cytokine production. Nature 377: 68-71

Calandra, T., L.A. Spiegel, C.N. Metz, R. Bucala (1998) Macrophage migration inhibitory factor is a critical mediator of the activation of immune cells by exotoxins of Gram-positive bacteria. Proc Natl Acad Sci USA 95: 11383 11388.

Calne, R.Y. (2000) Immunological tolerance - the liver effect. Immunol Rev 174: 280-282. 
Choufani, G., R. Ghanooni, C. Decaestecker, K. Delbrouck, P. Simon, M.P. Schuring, Y. Zick, S. Hassid, H.-J. Gabius, R. Kiss (2001) Detection of macrophage migration inhibitory factor (MIF) in human cholesteatomas and functional implications of correlations to recurrence status and to expression of matrix metalloproteinases-3/9, retinoic acid receptor-beta, and anti-apoptotic galectin-3. Laryngoscope 111: 1656-1662.

Cooper, T.G. (1999) Epididymis. Encyclopedia Reprod 2: 1-17.

Cropp, C.S., W.D. Schlaff (1990) Antisperm antibodies. Arch Immunol Ther Exp (Warsz) 38 . $31-46$.

David, J.R. (1966) Delayed hypersensitivity in vitro: its mediation by cell-free substances formed by lymphoid cell-antigen interaction. Proc Natl Acad Sci USA 56: 72-77.

Eickhoff, R., B. Wilhelm, H. Renneberg, G. Wennemuth, M. Bacher, D. Linder, R. Bucala, J. Seitz, A. Meinhardt (2001) Purification and characterization of macrophage migration inhibitory factor as a secretory protein from rat epididymis: evidences for alternative release and transfer to spermatozoa. Mol Med 7: $27-$ 35.

Eickhoff, R., C. Baldauf, H.W. Koyro, G. Wennemuth, Y. Suga, J. Seitz, R. Henkel, A. Meinhardt (2004) Influence of macrophage migration inhibitory factor (MIF) on the zinc content and redox state of protein-bound sulphydryl groups in rat sperm: indications for a new role of MIF in sperm maturation. Mol Hum Reprod 10: 605-611.

Frenette, G., C. Lessard, R. Sullivan (2002) Selected proteins of 'prostasome-like particles' from epididymal cauda fluid are transferred to epididymal caput spermatozoa in bull. Biol Reprod 67: 308-313.

Frenette, G., C. Lessard, E. Madore, M.A. Fortier, R. Sullivan (2003) Aldose reductase and macrophage migration inhibitory factor are associated with epididymosomes and spermatozoa in the bovine epididymis. Biol Reprod 69 . 1586-1592.

Frenette, G., C. Legare, F. Saez, R. Sullivan (2005) Macrophage migration inhibitory factor in the human epididymis and semen. Mol Hum Reprod 11: 575-582.

Goyal, H.O. (1985) Morphology of the bovine epididymis. Am J Anat 172: 155-172.

Hoffer, A.P., B.T. Hinton (1984) Morphological evidence for a blood-epididymis barrier and the effects of gossypol on its integrity. Biol Reprod 30: 991-1004.

Howards, S.S., S.J. Jessee, A.L. Johnson (1976) Micropuncture studies of the blood-seminiferous tubule barrier. Biol Reprod 14: 264-269.

Hudson, J.D., M.A. Shoaibi, R. Maestro, A. Carnero, G.J. Hannon, D.H. Beach (1999) A proinflammatory cytokine inhibits p53 tumor suppressor activity. J Exp Med 190: 1375-1382.
Kaltner, H., K. Seyrek, A. Heck, F. Sinowatz, H.J. Gabius (2002) Galectin-1 and galectin-3 in fetal development of bovine respiratory and digestive tracts. Comparison of cell type-specific expression profiles and subcellular localization. Cell Tissue Res 307: 35-46.

Kaunisto, K., S. Parkkila, T. Tammela, L. Ronnberg, H. Rajaniemi (1990) Immunohistochemical localization of carbonic anhydrase isoenzymes in the human male reproductive tract. Histochemistry 94: 381-386.

Kirchhoff, C. (1994) A major messenger ribonucleic acid of the rodent epididymis encodes a small glycosylphosphatidylinositol-anchored lymphocyte surface antigen. Biol Reprod 50: 896-902.

Kirchhoff, C., G. Hale (1996) Cell-to-cell transfer of glycosylphosphatidylinositol-anchored membrane proteins during sperm maturation. Mol Hum Reprod 2: 177-184.

Kleemann, R., A. Hausser, G. Geiger, R. Mischke, A. Burger-Kentischer, O. Flieger, F.J. Johannes, T. Roger, T. Calandra, A. Kapurniotu, M. Grell, D. Finkelmeier, H. Brunner, J. Bernhagen (2000) Intracellular action of the cytokine MIF to modulate AP-1 activity and the cell cycle through Jab1. Nature 408: 211-216.

Legendre, H., C. Decaestecker, N. Nagy, A. Hendlisz, M.P. Schuring, I. Salmon, H.-J. Gabius, J.C. Pector, R. Kiss (2003) Prognostic values of galectin-3 and the macrophage migration inhibitory factor (MIF) in human colorectal cancers. Mod Pathol 16: 491-504.

Manin, M., P. Lecher, A. Martinez, S. Tournadre, C. Jean (1995) Exportation of mouse vas deferens protein, a protein without a signal peptide, from mouse vas deferens epithelium: a model of apocrine secretion. Biol Reprod 52 . $50-62$.

Meinertz, H., L. Linnet, H. Wolf, T. Hjort (1991) Antisperm antibodies on epididymal spermatozoa. Am J Reprod Immunol 25: 158-162.

Meinhardt, A., M. Bacher, J.R. McFarlane, C.N Metz, J. Seitz, M.P. Hedger, D.M. de Kretser, R. Bucala (1996) Macrophage migration inhibitory factor production by Leydig cells: evidence for a role in the regulation of testicular function. Endocrinology 137: 5090-5095.

Meinhardt, A., M. Bacher, M.K. O’Bryan, J.R. McFarlane, C. Mallidis, C. Lehmann, C.N. Metz, D.M. de Kretser, R. Bucala, M.P. Hedger (1999) A switch in the cellular localization of macrophage migration inhibitory factor in the rat testis after ethane dimethane sulfonate treatment. J Cell Sci 112: 1337-1344.

Rosengren, E., R. Bucala, P. Aman, L. Jacobsson, G. Odh, C.N. Metz, H. Rorsman (1996) The immunoregulatory mediator macrophage migration inhibitory factor (MIF) catalyzes a tautomerization reaction. Mol Med 2: 143-149.

Rüsse, I., F. Sinowatz (1991) Lehrbuch der Embryologie der Haustiere. Berlin, Paul Parey.

Seitz, J., C. Keppler, U. Rausch, G. Aumüller (1990) Immunohistochemistry of secretory transglutaminase from rodent prostate. Histochemistry 93: 525-530.
Steinhoff, M., W. Eicheler, P.M. Holterhus, U. Rausch, J. Seitz, G. Aumüller (1994) Hormonally induced changes in apocrine secretion of transglutaminase in the rat dorsal prostate and coagulating gland. Eur J Cell Biol 65: 49-59.

Sullivan, R., F. Saez, J. Girouard, G. Frenette (2005) Role of exosomes in sperm maturation during the transit along the male reproductive tract. Blood Cells Mol Dis 35: 1-10.

Sun, H.W., J. Bernhagen, R. Bucala, E. Lolis (1996) Crystal structure at 2.6-A resolution of human macrophage migration inhibitory factor. Proc Natl Acad Sci USA 93: 5191-5196.

Suzuki, M., H. Sugimoto, A. Nakagawa, I. Tanaka, J. Nishihira, M. Sakai (1996) Crystal structure of the macrophage migration inhibitory factor from rat liver. Nat Struct Biol 3: 259-266.

Wada, S., S. Fujimoto, Y. Mizue, J. Nishihira (1997) Macrophage migration inhibitory factor in the human ovary: presence in the follicular fluids and production by granulosa cells. Biochem Mol Biol Int 41: 805-814.

Wada, S., T. Kudo, M. Kudo, N. Sakuragi, H. Hareyama, J. Nishihira, S. Fujimoto (1999) Induction of macrophage migration inhibitory factor in human ovary by human chorionic gonadotrophin. Hum Reprod 14: 395-399.

Waeber, G., T. Calandra, R. Roduit, J.A. Haefliger, C. Bonny, N. Thompson, B. Thorens, E. Temler, A. Meinhardt, M. Bacher, C.N. Metz, P. Nicod, R. Bucala (1997) Insulin secretion is regulated by the glucose-dependent production of islet beta cell macrophage migration inhibitory factor. Proc Natl Acad Sci USA 94: 4782 4787

Weiser, W.Y., P.A. Temple, J.S. Witek-Giannotti, H.G. Remold, S.C. Clark, J.R. David (1989) Molecular cloning of a cDNA encoding a human macrophage migration inhibitory factor. Proc Natl Acad Sci USA 86: 7522-7526.

Wilhelm, B., C. Keppler, G. Hoffbauer, F. Lottspeich, D. Linder, A. Meinhardt, G. Aumüller, J. Seitz (1998) Cytoplasmic carbonic anhydrase II of rat coagulating gland is secreted via the apocrine export mode. J Histochem Cytochem 46: 505-511.

Zeng, F.Y., W.Y. Weiser, H. Kratzin, B. Stahl, M. Karas, H.J. Gabius (1993) The major binding protein of the interferon antagonist sarcolectin in human placenta is a macrophage migration inhibitory factor. Arch Biochem Biophys 303: 74-80.

Zeng, F.Y., V. Gerke, H.J. Gabius (1994a) Characterization of the macrophage migration inhibitory factor-binding site of sarcolectin and its relationship to human serum albumin. Biochem Biophys Res Commun 200: 89-94.

Zeng, F.Y., H. Kratzin, H.J. Gabius (1994b) Migration inhibitory factor-binding sarcolectin from human placenta is indistinguishable from a subfraction of human serum albumin. Biol Chem Hoppe Seyler 375: 393-399. 